\title{
Correction to: Diseased Social Predators
}

\author{
Frank M. Hilker $^{1}$ (D) Marta Paliaga ${ }^{2} \cdot$ Ezio Venturino $^{3}$
}

Published online: 29 August 2018

(c) Society for Mathematical Biology 2018

\section{Correction to: Bull Math Biol (2017) 79:2175-2196 https://doi.org/10.1007/s11538-017-0325-y}

In the original article, the second author's family name was misspelled. The correct name is Marta Paliaga.

The original article can be found online at https://doi.org/10.1007/s11538-017-0325-y.

$凶 \quad$ Frank M. Hilker

frank.hilker@uni-osnabrueck.de

1 Institute of Environmental Systems Research, School of Mathematics/Computer Science,

Osnabrück University, Osnabrück, Germany

2 Scuola Politecnica, DIID, University of Palermo, Palermo, Italy

3 Department of Mathematics, "Giuseppe Peano", University of Torino, Turin, Italy 